
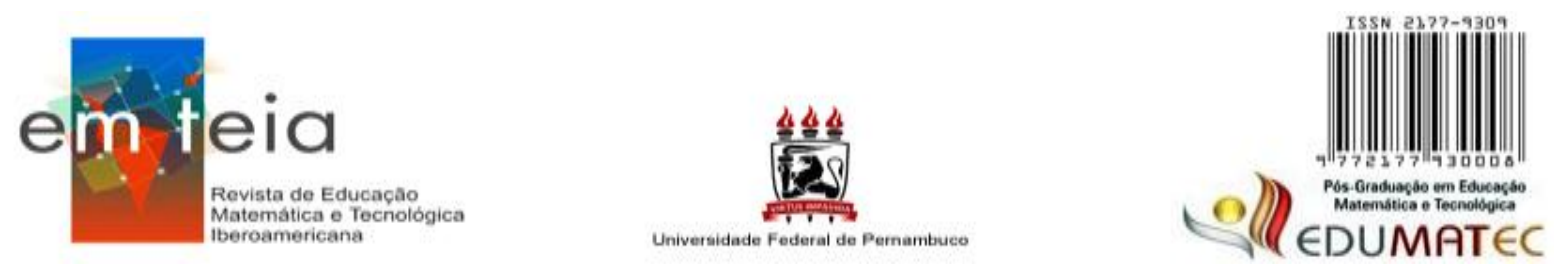

\title{
NÍVEIS DE CONHECIMENTO ESPERADOS DOS ESTUDANTES COMO AUXÍLIO PARA O ENSINO E APRENDIZAGEM DAS NOÇÕES DE PRIMITIVA DE UMA FUNÇÃO E INTEGRAL DE RIEMANN
}

\author{
LEVELS OF KNOWLEDGE EXPECTED OF STUDENTS AS AN AID \\ FOR THE TEACHING-LEARNING OF THE NOTIONS OF PRIMITIVE \\ OF A FUNCTION AND RIEMANN INTEGRAL
}

\author{
Marlene Alves Dias \\ maralvesdias@gmail.com \\ Pedro Mateus \\ pzulu1010@yahoo.com.br
}

\section{Resumo}

Este trabalho expõe parte de uma pesquisa sobre as noções matemáticas a ensinar nos Ensinos Fundamental, Médio e Superior e as relações destas com o saber, do ponto de vista antropológico, como meio de compreender questões associadas à transição entre as diferentes etapas da escolaridade. Apresentamos aqui uma investigação sobre as noções de primitiva de uma função e de integral de Riemann como setor de estudo dessa transição, tratando mais especificamente do tema 'cálculo de áreas'. Para tal, focalizamos sucintamente o referencial teórico da pesquisa: a Teoria Antropológica do Didático (de Chevallard) e os três níveis de conhecimento esperados dos estudantes (segundo Robert), níveis estes que conduzem a considerar ferramentas didáticas como as noções de quadro, mudança de quadro, ponto de vista e as representações simbólicas, aqui tratadas por meio de objetos ostensivos e não ostensivos. Também apresentamos a metodologia da pesquisa, assim como a grade de análise construída para avaliar como são tratados esses três níveis de conhecimento para o estudo das noções de primitiva de uma função e de integral de Riemann, bem como sua aplicação sobre o cálculo de áreas. Apresentamos um exemplo de aplicação da grade e os resultados da análise de dois livros didáticos e da macroavaliação ENADE que nos permitiram formular algumas conclusões sobre a importância de trabalhos que considerem os conhecimentos retrospectivos dos estudantes.

Palavras-Chave: Níveis de conhecimento. Teoria Antropológica do Didático. Primitiva de uma função e integral de Riemann.

\footnotetext{
Abstract

This article reports part of an investigation on the mathematical notions to be taught during primary, secondary, and tertiary education programs and the relationships between these notions and knowledge, from an anthropological point of view, with the purpose of elucidating issues associated with the transition between educational levels. To this end, the notions of primitive of a function and Riemann integral were focused as a study sector in this transition, more specifically within the topic 'calculation of areas'. Chevallard's Anthropological Theory of the Didactic and Robert's three levels of knowledge expected of students composed the core theoretical framework, of which a summary is
} 
provided. In the light of these levels, didactic tools such as the notions of setting, change of setting, point of view, and symbolic representations were addressed in terms of ostensive and non-ostensive objects. The research methodology is also reported, along with an analysis grid developed to evaluate how these three levels of knowledge are tackled for the study of primitive of a function and Riemann integral and how these notions are applied to the calculation of areas. An example of use of this grid is provided, together with an analysis of two textbooks and the results of the ENADE macroevaluation of Brazilian higher education programs. These data allowed us to draw conclusions on the importance of investigations that take into account the retrospective knowledge held by students.

Keywords: Levels of knowledge. Anthropological Theory of the Didactic. Primitive of a function and Riemann integral.

\section{Introdução}

Este trabalho é parte de uma pesquisa sobre as noções matemáticas a ensinar nos Ensinos Fundamental, Médio e Superior e as relações destas com o saber, do ponto de vista antropológico, como meio de compreender questões associadas à transição entre os Ensinos Fundamental (séries/anos iniciais e finais), Médio e Superior, bem como a possibilidade de conceber e experimentar um dispositivo de aprendizagem em torno dessas noções apoiado sobre um banco de tarefas integrando a utilização de recursos on-line e tecnologias.

Iniciamos lembrando que a deficiência hoje constatada do ensino de Ciências e Matemática em todos os níveis tem várias causas, e aqui propomos analisar apenas as carências relativas ao trabalho matemático, particularmente considerando-se as expectativas institucionais, tanto do ponto de vista do ensino (para o que são indicadas propostas e materiais a serem desenvolvidos com os estudantes, especialmente os livros didáticos avaliados pelo Programa Nacional do Livro Didático - PNLD) como do ponto de vista da aprendizagem (que em geral é avaliada no final de cada etapa escolar por meio de macroavaliações).

As expectativas institucionais foram analisadas por meio de livros didáticos, que foram considerados como propostas de ensino, e para tanto apresentamos os resultados das análises de dois livros (dentre um número maior de publicações analisadas) e a macroavaliação Exame Nacional do Desempenho dos Estudantes (ENADE), que corresponde aos conhecimentos que se espera que os estudantes tenham desenvolvido ao final do Ensino Superior.

Nosso objetivo é analisar as noções matemáticas a ensinar nos Ensinos Fundamental, Médio e Superior e suas relações com o saber, do ponto de vista antropológico, como um meio de compreender as questões associadas à transição entre as diferentes etapas da escolaridade, considerando-se particularmente a necessidade de encontrar novos meios de 
reflexão, que possibilitem melhorar o nível do ensino de Matemática para que os estudantes sejam capazes de aplicar seus conhecimentos na construção de novos conhecimentos e também nas atividades profissionais que futuramente desempenharão.

Para isso, considera-se que uma primeira reflexão, por parte dos professores, é compreender quais são os saberes necessários para o desenvolvimento de determinada noção ou conceito e quais são as relações desses saberes com os conhecimentos retrospectivos dos estudantes e com os novos conhecimentos que se espera desenvolver, ou seja, a relação entre os temas e tópicos associados a um domínio e setor da disciplina 'Matemática' para determinada etapa de sua escolaridade.

Neste trabalho, consideramos mais particularmente o tema 'cálculo de áreas', quando este é desenvolvido na disciplina 'Cálculo diferencial e integral' para o domínio do cálculo integral no setor 'primitiva de uma função e integral de Riemann'. Assim, empreendemos um estudo mais detalhado do ensino e da aprendizagem do tema 'cálculo de áreas' para o setor 'primitiva de uma função e integral de Riemann', para melhor compreender como trabalhar esta noção nos diferentes cursos do Ensino Superior, de modo a desenvolver no estudante uma flexibilidade que lhe permita ser capaz de resolver tarefas e problemas, tanto em nível mobilizável quanto disponível, isto é, que exigem uma aprendizagem que possibilite a aplicação dessas noções em tarefas e problemas dos diferentes domínios do conhecimento.

É importante observar que, em geral, a utilização de um conceito ou noção matemática em tarefas e problemas de outras ciências demanda que o estudante disponha desse conhecimento, uma vez que, no enunciado da tarefa, não é feito nenhum apelo explícito a tal conceito ou noção, o que exige que o estudante encontre em seu repertório de conhecimentos aquele que lhe permita resolver a tarefa.

Sendo assim, quando se elabora um plano de ensino para determinada disciplina, devem-se ter claras as questões acima levantadas para que se possa bem selecionar as noções associadas a determinado conteúdo, escolhendo quais devem ser aprofundadas e/ou direcionadas para as necessidades de interesse do curso. Não se pode trabalhar determinada noção sem levar em conta seu contexto, mas é preciso considerar o nível de conhecimento esperado do estudante em função do nível de conceitualização do conceito com o qual se está trabalhando, pois, para aplicar as noções de primitiva de uma função e de integral de Riemann, o estudante tem necessidade de conhecer suas técnicas, bem como mobilizar diversos conhecimentos matemáticos e conhecimentos específicos da disciplina na qual deverá aplicá-los. 
Verifica-se existirem poucos trabalhos voltados a esse fim e que tanto no Ensino Médio quanto no Superior os estudantes vivenciam grandes dificuldades, pois muitas vezes não dispõem dos conhecimentos matemáticos necessários a seu desenvolvimento escolar e profissional. Muitas dessas dificuldades estão associadas à não mobilização de conhecimentos matemáticos adquiridos no Ensino Fundamental, o que os conduz a uma situação de desinteresse, difícil de ultrapassar, uma vez que a falta de conhecimentos mobilizáveis tende a aumentar no decorrer das etapas da escolaridade.

Tal situação se reflete na qualidade do ensino de Ciências e de Matemática, tanto no Ensino Médio quanto no Superior. Sendo assim, escolhemos trabalhar a questão da flexibilidade entre formas de conhecimento e representações simbólicas, que corresponde à capacidade do estudante de articular seus conhecimentos em diferentes áreas e domínios, utilizar a representação simbólica mais adequada para resolver a tarefa que lhe é proposta, mudar de pontos de vista e recorrer às diferentes concepções de um mesmo conceito, sem que para isso seja necessário um apelo explícito. Pode-se, portanto, dizer que, quando o estudante é capaz de efetuar estes diferentes tipos de atividades, encontra-se preparado para trabalhar as noções matemáticas em um nível disponível, sendo capaz de reconhecer tanto as noções em jogo nas tarefas que lhe são propostas, quanto as representações mais adequadas para desenvolver o trabalho matemático em jogo na atividade.

Assim, ao analisar as condições necessárias para que o estudante articule de forma autônoma as noções de primitiva de uma função e de integral de Riemann - ou seja, os meios que o capacitam a resolver problemas que se colocam em sua vida escolar e profissional -, é possível encontrar formas de auxiliá-lo a superar as dificuldades encontradas particularmente nos primeiros anos dos cursos de Ciências Exatas, para os quais essas noções devem ser facilmente mobilizadas e articuladas com outros conhecimentos matemáticos para serem aplicadas a outras áreas de conhecimento. Um exemplo é a Estatística, atualmente uma ferramenta de trabalho para profissionais das mais diversas áreas, a qual requer a compreensão e interpretação de gráficos, assim como a interpretação de muitos resultados matemáticos que, muitas vezes, só podem ser compreendidos em sua plenitude através do conceito de integral, como é o caso das distribuições contínuas.

Inicia-se assim este trabalho com o seguinte questionamento:

1) Quais os conhecimentos matemáticos necessários para compreender as noções de primitiva de uma função e de integral de Riemann no Ensino Superior e poder aplicá-las de forma eficaz, quando necessário? 
2) Sobre que níveis de conhecimento (técnicos, mobilizáveis e disponíveis, segundo os define Robert) devem se fundamentar essas necessidades quando se deseja atingir uma aprendizagem com significado?

3) Como estão sendo trabalhados institucionalmente esses diferentes níveis de conhecimento?

4) O trabalho institucional que vem sendo desenvolvido possibilita que os estudantes atinjam a aprendizagem desejada?

Para abordar estas questões, investigamos alguns trabalhos didáticos e epistemológicos nos quais os três níveis de conhecimento têm papel central e relacionamos esses trabalhos com a Teoria Antropológica do Didático, de Chevallard.

Analisamos também o funcionamento institucional dos três níveis de conhecimento, segundo Robert (1997, 1998), para as noções de primitiva de uma função e de integral de Riemann. Para essa análise institucional, pesquisamos um conjunto de livros didáticos com propostas para o Ensino Superior de Matemática e Ciências.

Pretendemos com esta análise estudar mais detalhadamente o ensino e a aprendizagem das noções de primitiva de uma função e de integral de Riemann, referindo-nos mais particularmente ao cálculo de áreas, para melhor compreendermos como introduzir esse conteúdo de maneira a desenvolver no estudante uma flexibilidade que o capacite a resolver problemas tanto em nível mobilizável quanto disponível.

Escolhemos como referencial teórico central a abordagem em termos dos três níveis do conhecimento esperado dos estudantes, pois ela torna possível identificar quais conhecimentos devem ser privilegiados e quais são as outras noções em jogo das quais os estudantes devem dispor para que os professores possam construir sequências didáticas e engenharias didáticas adaptadas ao grupo com que estão trabalhando.

A seguir, apresentaremos brevemente a abordagem em termos dos três níveis de conhecimento, ressaltando outras abordagens que lhe dão suporte e, em seguida, consideraremos a Teoria Antropológica do Didático, de Chevallard, com o propósito de mostrar como a abordagem em termos dos três níveis de conhecimento pode auxiliar o professor a preparar sequências didáticas e engenharias didáticas que estejam em conformidade com as expectativas institucionais, pois a Teoria Antropológica auxilia a compreender quais são as relações pessoais esperadas dos estudantes em função das relações institucionais encontradas nas diferentes propostas e materiais de ensino. 


\section{Referencial teórico da pesquisa}

Para tratar das questões acima formuladas, trabalhamos a questão da flexibilidade por meio da articulação de quadros, segundo definição de Douady (1984, 1992); de objetos ostensivos e não ostensivos, à luz das definições de Chevallard (1994); e de pontos de vista, conforme definição de Rogalski (1995, 2001). Para analisar as expectativas institucionais, recorremos às noções de praxeologia, relações institucionais e pessoais, objetos ostensivos e não ostensivos, níveis de codeterminação e momentos didáticos, definidas por Chevallard (1992, 1994, 1996, 2012) e por Bosch e Chevallard (1999).

Consideramos, mais particularmente, os três níveis de conhecimento esperados dos estudantes, de acordo com a definição de Robert (1997, 1998), por tratar-se de uma análise mais global que leva em conta elementos, em termos de mudanças de quadros, manipulação de ostensivos e evocação de não ostensivos, que permitem identificar esses níveis de conhecimento.

Além disso, estudamos as relações institucionais existentes e as relações pessoais esperadas dos estudantes, visando mostrar a importância de um trabalho flexível em que se articulem esses três níveis de conhecimento quando se deseja que os estudantes sejam capazes de aplicá-los em tarefas em que devam mobilizar ou dispor de conhecimentos sobre determinada noção e sobre aquelas que lhe estão associadas.

Apresentaremos a seguir uma breve definição das noções didáticas utilizadas no desenvolvimento da pesquisa.

\section{A noção de quadro e mudança de quadro}

Douady $(1984,1992)$, baseando-se em uma análise epistemológica sobre o trabalho do matemático profissional, evidencia a dualidade dos conceitos matemáticos - os quais, em geral, funcionam como ferramentas implícitas e, em seguida, explícitas da atividade matemática, antes de adquirirem o status de objeto e de serem trabalhados como tal - e o papel desempenhado pelas mudanças de quadro nas atividades e na produção matemática.

Segundo Douady $(1984,1992)$, uma ferramenta implícita corresponde a um conceito em elaboração, processo este que pode durar vários anos. Já uma ferramenta explícita está associada a um conceito ou a uma noção utilizada intencionalmente para resolver um problema. Um objeto, por sua vez, é definido como um componente cultural que ocupa um lugar bem determinado no complexo edifício do saber matemático, sendo reconhecido socialmente. 
O objeto matemático, tal como definido por Douady $(1984,1992)$, é parte de um edifício mais amplo, que é o saber matemático, constituindo assim o que ela denomina quadro, que corresponde a um ramo da Matemática, das relações entre os objetos, de suas formulações eventualmente diversas e das imagens mentais que lhes são associadas. As imagens mentais são essenciais, pois funcionam como ferramentas dos objetos do quadro. Dois quadros podem conter os mesmos objetos, mas diferir pelas imagens mentais e problemáticas desenvolvidas.

Douady define as mudanças de quadro como meios para se obterem formulações diferentes de um problema, que podem ou não ser equivalentes, mas que possibilitam um novo acesso às dificuldades encontradas e permitem utilizar novas ferramentas e técnicas que não eram adequadas à formulação inicial. As traduções de um quadro em outro terminam sempre em resultados desconhecidos, em novas técnicas, permitindo assim a criação de novos objetos matemáticos, enriquecendo tanto o quadro original como os quadros auxiliares de trabalho.

\section{A noção de ponto de vista}

Segundo Rogalski (1995, 2001), dois pontos de vista diferentes sobre um objeto matemático são duas diferentes maneiras de observá-lo, de fazê-lo funcionar e, eventualmente, de defini-lo. Nesse sentido, observar um objeto em diferentes quadros é considerar diferentes pontos de vista, embora se possam considerar vários pontos de vista em um mesmo quadro.

\section{Objetos ostensivos e não ostensivos}

Após considerar que em toda atividade humana somos chamados a realizar diferentes tipos de tarefas e que para cada uma delas existe uma técnica, Chevallard (1994) apresenta as seguintes questões: de que é feita uma técnica? De que ingredientes se compõe? Em que consiste a "execução" de uma técnica?

Para respondê-las, Chevallard (1994) distingue dois tipos de objetos: os ostensivos e os não ostensivos. Os primeiros são objetos que têm para nós uma forma material, sensível. Exemplos: objetos materiais (caneta, compasso etc.); gestos (ostensivos gestuais); palavras, e mais genericamente o discurso (ostensivos discursivos); esquemas, desenhos, grafismos (ostensivos gráficos); escritas e formalismos (ostensivos escriturais).

A característica dos ostensivos é que podem ser manipulados, não só no sentido tátil estrito (como um compasso, uma caneta etc.), mas também em sentido amplo (pela voz, pelo 
olhar etc.). Ao contrário, os objetos não ostensivos, que denominamos usualmente noções, conceitos, ideias etc., não podem ser manipulados, mas só evocados por manipulação dos ostensivos associados. Chevallard (1994) observa existir uma dialética necessária entre ostensivos e não ostensivos, pois os primeiros são manipulados por meio de regras, cuja distinção é feita pelos não ostensivos, enquanto estes últimos são evocados por meio da manipulação dos ostensivos.

\section{Os três níveis de conhecimento esperados dos estudantes}

Antes de apresentar a definição desses três níveis de conhecimento, conforme definição de Robert (1997, 1998), é importante observar que eles dependem do nível de conceituação em que se está trabalhando. Segundo Robert (1997, 1998), os níveis de conceituação são os marcos que podemos identificar ao longo do ensino das noções de determinado campo conceitual. Muitas noções matemáticas podem ser abordadas em vários níveis de conceituação, sempre parcialmente encaixados, sendo que os objetos iniciais mudam, tornando-se mais gerais, o que permite introduzir novas estruturas, mais ricas, requerendo, porém, um novo formalismo. Em geral, os exercícios ditos teóricos de determinado nível correspondem aos teoremas do nível seguinte. Dessa forma, várias ordens de apresentação são sempre possíveis, inexistindo uma hierarquia absoluta entre esses níveis, que, pelo menos durante os estudos, dependem apenas do ensino efetivo.

Após considerar que o ensino das noções matemáticas associadas a um campo conceitual depende da escolha da ordem de apresentação, Robert $(1997,1998)$ define os três níveis de conhecimento esperados dos estudantes: o técnico, o mobilizável e o disponível.

O nível técnico corresponde a um trabalho isolado, local e concreto. Está relacionado principalmente às ferramentas e definições utilizadas em determinada tarefa.

Para a noção de integral, pode-se considerar o seguinte exemplo:

- Determinar a primitiva de uma função de referência, isto é, a integral das funções $\operatorname{sen}(x)$, $\cos (x), e^{x}, x^{n} \operatorname{com} n \neq-1$.

O nível mobilizável corresponde a um início de justaposição de saberes de certo domínio, podendo até corresponder a uma organização. Vários métodos podem ser mobilizados. O caráter 'ferramenta' e o caráter 'objeto' do conceito estão em jogo, mas o que se questiona é explicitamente pedido. Se um saber é identificado, ele é considerado mobilizado se é acessível, isto é, se o estudante o utiliza corretamente. Exemplo:

- Utilizar um dos métodos de integração de uma função: o estudante deverá reconhecer quando se trata de um produto de funções, para aplicar o método de integração por partes, 
ou de uma função composta, para utilizar o método de integração por substituição, que em alguns casos necessita das substituições trigonométricas. Neste exemplo, mesmo o trabalho específico de utilizar um dos métodos de integração deve ser mobilizado pelo estudante: as noções de derivada, função composta, produto de funções e relações trigonométricas devem estar disponíveis para desenvolver a tarefa proposta.

O nível disponível corresponde a conseguir responder corretamente o que é proposto sem indicações, a poder dar contraexemplos (encontrando-os ou criando-os), mudar de quadro (fazer relações) e aplicar métodos não previstos. Esse nível de conhecimento está associado à familiaridade, ao conhecimento de situações de referência variadas que o estudante sabe que conhece (servem de terreno de experimentação), ao fato de dispor de referências, de questionamentos, de uma organização. Pode funcionar para um único problema ou possibilita fazer resumos. Exemplos:

- Calcular a área de um conjunto do plano limitado por duas funções. Neste caso, o estudante deve construir o gráfico e interpretar a representação obtida, fazendo a passagem do ostensivo gráfico para o ostensivo simbólico de uma integral definida, para em seguida calcular a integral.

- Dada a velocidade de um corpo como função do tempo $t$, calcular o espaço percorrido pelo corpo em determinado intervalo. Este exemplo é uma aplicação em Física da noção de integral, que permite calcular o espaço por meio da área do gráfico da velocidade, como é feito no Ensino Médio para os movimentos uniformes, mas que exige a noção de integral quando se trabalha com funções em que as áreas não podem ser calculadas por meio das fórmulas disponíveis de Geometria. Nesse momento, o professor pode aproveitar os conhecimentos de Física dos estudantes para mostrar a importância do conceito de integral, que possibilita calcular qualquer área.

Os exemplos acima conduziram a proposta de análise das expectativas institucionais e, para tanto, recorremos à Teoria Antropológica do Didático, de Chevallard, e em particular às noções de praxeologia, relações institucionais e pessoais, níveis de codeterminação e momentos didáticos.

\section{Teoria Antropológica do Didático}

Chevallard (2012) distingue o didático e a didática, definindo o primeiro como a intenção de qualquer instância (pessoa ou instituição) de fazer alguma coisa com a finalidade de que outra instância aprenda algo. Assim, toda situação que contém essa intenção é 
denominada situação didática. A didática, por sua vez, é definida pelo autor como a ciência das condições e restrições da difusão dos conhecimentos na sociedade.

Em determinada sociedade, portanto, há no seio de uma instituição um controle ativo, mais ou menos precário, mais ou menos vigilante, das maneiras de pensar, de dizer, de pronunciar, de agir, que supõe o didático. Esse controle social, no entanto, causa uma interdição parcial, pois, em essência, prescreve, isto é, ele nos diz o que devemos pensar e como devemos agir - ou seja, para não proibir, prescreve.

Havendo definido a didática, Chevallard (2012) introduz a noção de sistema didático como realidade social que reúne três entidades: um estudante $x$, um professor $y$ e um desafio didático $\boldsymbol{\vee}$, sistema este que pode ser indicado por $S(x ; y ; \boldsymbol{\vee})$. Genericamente, a instância 'estudante' será indicada por $X$, correspondendo ao conjunto dos membros $x$; a instância ‘ajuda ao estudo' será indicada por $Y$, cujos membros são representados por $y$; e o desafio didático $\vee$ é a obra designada por $Y$ para estudar e para fazer com que $X$ estude. Observamos aqui que Chevallard (1998) define 'obra' como uma parte qualquer de um complexo de organizações praxeológicas.

Segundo Chevallard (1997), a noção de organização praxeológica, ou praxeologia, corresponde aos tipos de tarefas $(T)$ que, para serem executadas, necessitam de uma maneira de fazer, maneira esta que o autor denomina 'técnica' $(\tau)$. A associação tarefa-técnica é definida como um saber fazer que não sobrevive isoladamente, solicitando um ambiente tecnológico-teórico que equivale a um saber formado por uma tecnologia ou discurso tecnológico $(\theta)$ - ou seja, um discurso racional que justifica a técnica e a torna compreensível - e de uma teoria $(\Theta)$ que justifica e esclarece a tecnologia utilizada. O sistema composto por tipo de tarefa, técnica, tecnologia e teoria $[T, \tau, \theta, \Theta]$ constitui o que Chevallard denomina organização praxeológica, ou praxeologia, a qual articula uma parte prático-técnica, que corresponde ao saber fazer, a uma parte tecnológica teórica, que corresponde ao saber. A base de toda praxeologia é constituída por um sistema de tarefas em torno das quais se desenvolvem e se organizam técnicas, tecnologias e teorias.

Após considerarmos a noção de organização praxeológica ou praxeologia, passamos à definição de organização matemática e didática e, em seguida, consideramos os momentos de estudo que devem ser levados em conta em uma organização didática.

Chevallard (1997) define organização matemática como uma organização praxeológica de natureza matemática, sendo constituída de um ou vários tipos de tarefas matemáticas, mais ou menos bem identificadas, que exigem a criação de técnicas matemáticas mais ou menos bem adaptadas e mais ou menos justificadas por tecnologias matemáticas mais 
ou menos sólidas, sendo as tecnologias desenvolvidas no âmbito de uma teoria matemática mais ou menos explícita.

Assim, segundo Chevallard (1997), é tarefa do professor a concepção e organização de dispositivos de estudo, assim como a gestão de seu ambiente, ou seja, uma das tarefas do professor consiste em determinar, a partir das indicações fornecidas pelos programas oficiais, as organizações matemáticas a estudar, especificando para cada uma delas seu conteúdo preciso, a base dos tipos de tarefas que elas contêm e o grau de desenvolvimento a dar aos componentes técnicos, tecnológicos e teóricos.

A noção de organização didática é definida por Chevallard (1997) como a reconstrução ou a transposição da organização matemática na sala de aula. Para o autor, quaisquer que sejam os caminhos seguidos, tem-se necessariamente um momento em que determinado gesto didático deve ser cumprido, o que Chevallard (1997) denomina momentos didáticos ou momentos de estudo. $\mathrm{O}$ autor considera que tais momentos são uma realidade orgânica antes de serem uma realidade cronológica e devem ocorrer na ocasião adequada, podendo acontecer várias vezes.

Ainda segundo Chevallard (1997), na organização didática é tarefa do professor propor tarefas de ajuda ao estudo e dirigir o estudo e ensino de forma que se possam colocar em prática determinadas técnicas didáticas.

Assim, é importante apresentar os momentos didáticos ou momentos de estudo indicados por Chevallard (1997) como os gestos didáticos que devem ser cumpridos em determinada organização didática. Observamos que o autor distingue seis momentos, explicitando que estes podem repetir-se várias vezes em uma mesma organização didática.

- O primeiro momento de estudo é o do primeiro encontro com a organização matemática estudada.

- O momento de exploração do tipo de tarefa e de elaboração de uma técnica corresponde ao estudo e à realização de um problema de tipo dado. Acompanha sempre a constituição de um embrião de técnica, a partir da qual uma técnica mais desenvolvida poderá eventualmente emergir. $\mathrm{O}$ estudo de um problema particular aparece não como um fim, mas como um meio para que tal técnica de resolução se constitua. Assim, está vinculado a uma dialética fundamental: estudar problemas é um meio de criar e de elaborar uma técnica, que será o meio de resolver quase automaticamente problemas deste tipo.

- O momento da elaboração tecnológico-teórica relativa a uma técnica tem relação estreita com os demais momentos. Assim, desde o primeiro encontro com a organização matemática, há uma relação com um ambiente tecnológico teórico anteriormente elaborado 
ou com germes de um ambiente a ser criado, que se tornará mais claro por meio de uma relação dialética com a emergência da técnica.

- O momento de trabalho da técnica deve aperfeiçoar a técnica, tornando-a mais eficaz e mais confiável, além de aumentar o domínio que dela temos. Esse momento de provar a técnica coloca-se, em particular, para um ou vários corpora de tarefas adequadas, tanto qualitativa quanto quantitativamente.

- No momento da institucionalização o objeto de estudo é especificado, o que corresponde exatamente à elaboração da organização matemática, distinguindo principalmente, de um lado, os elementos que contribuíram para sua construção, embora sem terem sido integrados, e, por outro, os elementos que entraram de maneira definitiva na organização matemática visada.

- O momento da avaliação se articula com o momento da institucionalização.

Consideramos ainda as noções de relações institucionais e pessoais definidas por Chevallard (1992, 1998). Segundo o autor, a organização do estudo supõe uma modelagem mínima da estática e, sobretudo, da dinâmica cognitiva. Assim, na perspectiva antropológica, a primeira noção fundamental é a de objeto, que corresponde a toda entidade, material ou imaterial, que existe para pelo menos um indivíduo. Desse modo, a noção de objeto é a mais geral, pois, segundo Chevallard, tudo é objeto - inclusive as pessoas. Cita como exemplos de objetos o número sete, o algarismo 7, a noção de pai e também a de pai que passeia com seu filho, as ideias de perseverança, de coragem ou de virtude, a noção de derivada etc.

Chevallard (1998) considera que toda obra $O$ é um objeto, explicitando que uma obra corresponde a qualquer parte de um complexo de organizações praxeológicas e, mais especificamente, pode ser somente um componente material, como um livro, uma mesa, um datashow.

Após definir objeto, Chevallard (1998) introduz a segunda noção fundamental, que é a de relação pessoal de um indivíduo $x$ com um objeto $o$, que corresponde à expressão pela qual designamos o sistema - representado por $R(x, o)$-, de todas as interações, sem exceção, que $x$ pode ter com o objeto $o$, ou seja, $x$ pode manipulá-lo, utilizá-lo, falar sobre ele, sonhar com ele etc. Assim, dizemos que $o$ existe para $x$ se este tem uma relação pessoal com $o$ ou, ainda, se sua relação pessoal com esse objeto é não vazia - o que se indica por $R(x, o) \neq \varnothing$.

A terceira noção fundamental é a de pessoa, que é definida pelo par formado por um indivíduo $x$ e o sistema de relações pessoais $R(x, o)$ num dado momento da história de $x$. Dessa 
forma, quando um objeto $o$ existe para uma pessoa $x$, ou seja, quando $R(x, o) \neq \varnothing$, dizemos que $x$ conhece $o$ e que a relação $R(x, o)$ indica a maneira em que $x$ conhece $o$.

Ao introduzir a quarta noção - a de instituição -, o autor explicita que as instituições são obras de tipo particular, ou seja, uma instituição é um dispositivo social "total”, que pode ter somente uma extensão reduzida no espaço social (existem microinstituições), mas que permite e impõe a seus sujeitos, isto é, às pessoas que vêm ocupar diferentes posições oferecidas na instituição $I$, envolvendo maneiras próprias de fazer e, mais amplamente, adotando praxeologias determinadas. Desse modo, por exemplo, um livro didático é uma obra e a classe que permite a utilização desse livro é uma instituição, em que as duas posições essenciais são a de professor e a de estudante, da mesma maneira como o estabelecimento, no qual existem outras posições, também é uma instituição englobante, que fusiona diversas posições, a qual é o sistema educativo.

Chevallard (1998) esclarece que a relação pessoal de $x$ com o objeto $o$ é criada ou alterada por meio da entrada de $x$ em certas obras $O$, de cuja composição participa $o$, e essas obras vivem em determinadas instituições em que $x$ poderá ocupar a posição $p$. Assim, desde o nascimento, todo indivíduo se sujeita a múltiplas instituições: ele é ao mesmo tempo submetido e sustentado pelas instituições (tais como sua família), nas quais se torna um sujeito.

Assim, a "teoria do conhecimento" esboçada para os indivíduos é transferida às instituições, ou seja, dado um objeto $o$, uma instituição $I$ e uma posição $p$ em $I$, denominamos relação institucional a de $o$ em posição $p$, e a indicamos por $R_{I}(p, o)$ a relação com o objeto $o$ que deveria ser, idealmente, aquela dos sujeitos de $I$ em posição $p$. Dizer que $x$ é um bom sujeito de $I$ em posição $p$ é o mesmo que afirmar que a relação pessoal do indivíduo $x$ está em conformidade ou é adequada à relação institucional em posição $p$, que indicamos por $R(x, o) \cong$ $R_{I}(p, o)$. Para diversos objetos $o$, temos $R_{I}(p, o)=\varnothing$, isto é, os sujeitos de $I$ em posição $p$ não são conduzidos a conhecer o objeto $o$.

Ao se tornar sujeito de $I$ em posição $p$, um indivíduo $x$, que é sempre uma pessoa, submete-se às relações institucionais $R_{I}(p, o)$, que irão (re)modelar, (re)formar suas relações pessoais, ou seja, se $o$ existe para os sujeitos que estão na posição $p$, a relação pessoal de $x$ com $o, R(x, o)$ tende a ser semelhante à relação institucional $R_{I}(p, o)$, a menos que $x$ se revele mau sujeito de $I$. De forma geral, nossas relações pessoais são fruto de nossa história de sujeições institucionais passadas e presentes. 
Consideraremos agora a noção de níveis de codeterminação definidos por Chevallard (2002, 2007). Chevallard (2002) observa que o problema de fazer funcionar organizações didáticas concebidas segundo determinado ponto de vista conduz a enfrentar restrições que distorcem a estrutura e eliminam as funções quando deixam de ser apenas um mundo no papel. Assim, o autor explicita essas restrições associando as diferentes organizações matemáticas à hierarquia dos níveis de codeterminação, mostrando que seu interesse é viabilizar a triagem das restrições que dirigem o estudo escolar e a escolha daquelas que permitam evitar um desequilíbrio muito flagrante.

Dessa forma, Chevallard (2002) parte da afirmação de que as restrições indicadas acima se devem ao fato de que uma organização matemática não se faz em um vazio de obras, pois uma organização matemática pontual praticamente não é encontrada no desenvolvimento de estudos reais, já que essa abstração existe para o estudante, que em geral é avaliado sobre tipos de tarefas que, para ele, correspondem a um tópico completo quase independente dos outros. Já para o professor, há uma unidade em torno de uma tecnologia que tem status de tema de estudo e que se agrupa em uma organização regional, que corresponde ao amálgama de organizações locais, admitindo uma mesma teoria, que é associada ao setor de estudo. Existem ainda níveis superiores de determinação de uma organização matemática, ou seja, o correspondente ao amálgama de várias organizações regionais, que conduzem a uma organização global identificada a um domínio de estudo, cujo conjunto é amalgamado em uma disciplina.

Chevallard (2002) observa que os professores, em geral, referem-se apenas aos níveis de tópico e de tema, pois nas organizações didáticas escolares são frequentemente poucas as possibilidades de atuar sobre os outros níveis. Para ampliar essa condição, o autor traz como exemplo iniciar uma aula apresentando o programa de estudos da classe para o ano escolar, o que permite ao professor expor cada domínio que compõe o programa e completá-lo no decorrer do ano com uma apresentação dos setores de estudo que compõem estes domínios, situando temas e tópicos que serão estudados na sequência.

O autor também ressalta que, se o professor não localiza temas e tópicos nos setores e domínios de estudo e segue o programa introduzindo-os um após o outro como uma fila indiana, irá provocar uma atomização do material de estudo que contrasta com a ambição original que é ensinar Matemática.

Desse modo, conforme Chevallard (2002), encontramos um fenômeno ecológico central, o da codeterminação das organizações matemáticas e didáticas, pois a ausência da relação do tópico ou tema com os níveis superiores de setores e de domínios, além da própria 
disciplina, torna impossível pensar a relação de motivação entre os tipos de tarefas, ou seja, a organização do estudo de um tópico ou tema conduz a considerar os níveis superiores da hierarquia de determinação matemática.

Assim, se os professores ficam confinados ao nível 'tema', as diferentes esferas da noosfera cuidam dos níveis superiores - setores, domínios, disciplinas. A inscrição de determinados domínios da Matemática passa a ser controlada por instâncias de capital científico e político.

$\mathrm{Na}$ escala constituída por tópicos, temas, setores, domínios e disciplinas, juntam-se ainda níveis suplementares (sociedade, escola, pedagogia) que advêm de uma construção histórica. Cada nível determina a forma de construção e reconstrução das organizações matemáticas e didáticas por meio dos pontos de apoio que oferecem e das restrições que impõem.

O nível pedagógico é aquele em que se termina a ação da noosfera disciplinar, uma vez que as restrições pedagógicas tomam a forma de um conjunto de meios de estudo impostos e alocados em todo estudo escolar, com algumas exceções, que convém negociar com a autoridade pedagógica.

Mas o esquema de níveis de codeterminação matemática não termina no nível pedagógico. Este representa apenas a fronteira entre a noosfera, que é composta de especialistas em Pedagogia que propõem a lei sem se preocupar com os decretos de aplicação, e onde reina o que o autor denomina política.

Além do nível pedagógico, encontramos o nível 'escola', isto é, o nível de restrições e pontos de apoio próprios da instituição escolar. Assim, a escola é definida como instituição social dedicada ao estudo, onde se suspende temporariamente o fluxo das atividades comuns da vida para estudar, ou seja, desconstruir e reconstruir as praxeologias da vida.

No nível 'sociedade' há uma enorme quantidade de restrições e, como exemplo, o autor apresenta o fato de que uma sociedade pode compreender a instrução dada em sua escola sob pontos de vista diferentes, que não são didaticamente equivalentes, isto é, que não criam as mesmas condições na classe para um mesmo tópico de estudo.

Chevallard (2007) inclui na escala de níveis de codeterminação o nível 'civilização' e, após considerar que as praxeologias são componentes dos diferentes habitats, elucida que, no processo de difusão praxeológica, as condições e restrições são cultivadas e centralizadas com a ajuda da escala de níveis de codeterminação, pois essas condições e restrições podem situarse em determinado nível da escala e exprimir-se em outro, o que não nos permite isolar o que se passa na classe do conjunto do sistema de ensino. Assim, os níveis de codeterminação 
descrevem as relações recíprocas entre os diferentes níveis do sistema didático e são representados da seguinte forma: tópicos $\leftrightarrow$ temas $\leftrightarrow$ setores $\leftrightarrow$ domínios $\leftrightarrow$ disciplinas $\leftrightarrow$ pedagogia $\leftrightarrow$ escola $\leftrightarrow$ sociedade $\leftrightarrow$ civilização. Esta representação evidencia que os níveis de codeterminação são percebidos nos dois sentidos, ou seja, se modificamos as condições e restrições de determinado nível, teremos repercussões sobre os demais.

A partir do referencial teórico descrito acima, construímos a metodologia da pesquisa para analisar o tema 'cálculo de áreas' que é desenvolvido na disciplina 'Cálculo diferencial e integral' para o domínio 'cálculo integral' no setor 'primitiva de uma função e integral de Riemann' e determinar os tópicos associados a esse tema com os respectivos níveis de conhecimento esperados dos estudantes em termos dos conhecimentos retrospectivos e novos conhecimentos necessários para o desenvolvimento das tarefas associadas ao tema de estudo.

\section{Metodologia da pesquisa}

Esta pesquisa qualitativa centrada no estudo de documentos compôs-se de duas fases.

Na primeira fase, procuramos compreender os níveis de conhecimento necessários para se alcançar uma aprendizagem com significado. Para tanto, elaboramos uma grade de análise que permitisse verificar os níveis privilegiados para a abordagem das noções de primitiva de uma função e de integral de Riemann. Essa grade foi aplicada a livros didáticos, com o objetivo de observar as regularidades e diferenças institucionais existentes em suas propostas.

Isso possibilita estabelecer os diferentes tipos de tarefas associados às noções de primitiva de uma função e de integral de Riemann que intervêm nos cursos de Matemática e Ciências para estudantes do Ensino Superior, isto é, essa análise permite estabelecer o funcionamento institucional existente em relação à introdução das noções de primitiva de uma função e de integral de Riemann, auxiliando também na reflexão sobre as diferentes formas de tratar essa questão nos diferentes cursos de Ciências do Ensino Superior.

$\mathrm{Na}$ segunda fase, analisamos as tarefas sobre primitiva de uma função e integral de Riemann da prova do ENADE de 2014 para o curso de Licenciatura em Matemática, com a finalidade de verificar se as propostas institucionais correspondem às expectativas de desempenho dos estudantes que serão os futuros professores de Matemática da Educação Básica. 


\section{A grade de análise}

O propósito dessa grade foi servir como instrumento que permitisse analisar os diferentes níveis de conhecimento exigidos dos estudantes num curso de introdução ao cálculo, quando se trabalha com as noções de primitiva de uma função e de integral de Riemann.

Esse tipo de grade propicia analisar os três níveis de conhecimento (técnico, mobilizável e disponível) esperados dos estudantes:

- em função das tarefas associadas às noções de primitiva de uma função e de integral de Riemann encontradas em um curso de introdução ao cálculo;

- em função das variáveis dessas tarefas, para as quais se dá ênfase ao nível de conhecimento pedido explicitamente no enunciado e aos diferentes níveis de conhecimento de outras noções que devem ser utilizadas para a solução da tarefa.

Primeiramente, estudaram-se as diferentes tarefas usualmente encontradas para a introdução das noções de primitiva de uma função e de integral de Riemann e, em seguida, identificaram-se os diferentes níveis de conhecimento exigidos dos estudantes na solução dessas tarefas. Para especificar a tarefa em relação aos diferentes níveis de conhecimento exigidos, consideraram-se as seguintes variáveis das tarefas:

- nível de conhecimento exigido na tarefa;

- quadros em que a tarefa é enunciada;

- objetos ostensivos necessários à solução da tarefa;

- níveis de conhecimento necessários à execução da tarefa em relação aos não ostensivos que serão utilizados.

\section{Exemplo de funcionamento da grade em uma tarefa}

É proposta a tarefa: calcule a área do conjunto $A$ de todos os pontos do plano, tais que: $0 \leq y \leq \cos (3 x)$, com $0 \leq x \leq 2 \pi$.

Nesta tarefa particular, as variáveis são as seguintes:

Níveis do conhecimento exigido na tarefa: mobilizável e disponível.

Quadros em que a tarefa é enunciada: geometria analítica e trigonometria.

Objetos ostensivos necessários à solução da tarefa: para responder à questão, os estudantes devem passar dos ostensivos da linguagem natural e do ostensivo simbólico 
em intervalos para o ostensivo simbólico de função, quando se considera a variação de $y$, e para o ostensivo simbólico da geometria analítica em que os extremos do intervalo de $x$ são considerados como as equações de duas retas. A partir desses ostensivos, deve-se fazer a passagem para o ostensivo gráfico, o que torna possível interpretar a variação da função e dos limites superior e inferior.

Níveis de conhecimento necessários para a execução da tarefa em relação aos não ostensivos que serão utilizados: para responder à questão, o estudante deverá dispor de conhecimentos sobre a conversão da representação das funções $y=0$ e $y=\cos (3 x)$ dadas por suas fórmulas em seus respectivos gráficos e da conversão do intervalo $0 \leq x$ $\leq 2 \pi$ através da faixa entre as retas $x=0$ e $x=2 \pi$. A partir do gráfico, podem-se considerar os limites inferior e superior e, integrando a função, determinar a área pedida.

Se a tarefa é proposta em um capítulo em que se estuda a integral de Riemann e, em particular, o cálculo das áreas, o nível exigido é mobilizável em relação à noção de integral definida, mas se essa tarefa é proposta sem nenhum comentário sobre a noção de integral, pode-se considerar que o nível necessário é o disponível.

Nos dois casos, a noção de função cosseno e seu gráfico devem ser disponíveis, assim como a integral da função cosseno e a técnica de integração por substituição.

Se em lugar da função $\mathrm{y}=\cos (3 x)$ o enunciado considera apenas a função $\cos (x)$, o estudante deverá dispor apenas dos conhecimentos associados à noção de função cosseno e seu gráfico e da integral da função cosseno.

Este exemplo mostra que o professor pode escolher a tarefa desejada em função dos conhecimentos retrospectivos de seus estudantes.

Para melhor compreender o nível em que se podem desenvolver as noções de primitiva de uma função e de integral de Riemann nos cursos de introdução ao cálculo para Ciências, quando se trabalha este setor, mais particularmente, o tema 'cálculo de áreas', analisa-se, via livro didático, qual o nível que se pode esperar como disponível para os estudantes que terminam esse curso introdutório.

\section{A análise dos livros didáticos}

Embora diversos livros didáticos tenham sido analisados, optamos por apresentar aqui os resultados de apenas dois, que tendem a seguir o mesmo modelo: após introduzir as noções de números reais, funções, limite e continuidade, focalizam a noção de derivada introduzindo 
as funções de referência e considerando os pontos de vista definidos por Thurston (1995): o infinitesimal, que permite pensar na derivada como a relação de mudança infinitesimal do valor da função na mudança infinitesimal da variável; o simbólico, para o qual a derivada de $x^{n}$ é $n x^{n-1}$, a derivada de $\operatorname{sen}(x)$ é $\cos (x)$, a derivada de $f \circ g$ é $f^{\prime}$ o ${ }^{*} g^{\prime}$ etc.; e o geométrico, no qual a derivada é a inclinação da tangente ao gráfico, se o gráfico possui uma tangente nesse ponto, sendo que a taxa de variação corresponde à velocidade instantânea de $f(t)$ se $t$ é o tempo.

Após a introdução das noções de limite e derivada de uma função de uma variável real com valores reais, os livros didáticos geralmente introduzem a noção de primitiva de uma função, os métodos de integração, a integral de Riemann e a aplicação desta ao cálculo de áreas, o qual requer, como se pode constatar observando o exemplo apresentado na grade de análise, que se disponha de conhecimentos retrospectivos associados aos estudos matemáticos desenvolvidos no Ensino Médio.

Alguns autores, após introduzirem a noção de primitiva, definem primeiro a integral de Riemann para, em seguida, passar aos métodos de integração. Em todos os livros analisados, e principalmente nos dois aqui focalizados, verifica-se uma preocupação em trabalhar os três níveis de conhecimento, sendo o nível técnico o que aparece em primeiro plano, o que pode levar alguns professores a privilegiar somente esse trabalho. Trata-se aqui de uma escolha do professor. Desta forma, a análise foi estruturada em torno das seguintes questões:

- Como são introduzidas as noções de primitiva de uma função e de integral de Riemann, quais ostensivos são utilizados e como estes se articulam?

- Que pesos respectivos ocupam os níveis técnico, disponível e mobilizável nas tarefas propostas aos estudantes?

- Existe um discurso tecnológico teórico no curso e no tratamento dos exemplos que o acompanham que auxilie os estudantes no desenvolvimento dos níveis mobilizável e disponível?

\section{Resultados da análise dos livros didáticos}

\section{Análise da obra Um curso de cálculo, de Hamilton Luiz Guidorizzi (2004)}

Após introduzir as noções de números reais, funções, limite e continuidade, derivadas e estudo da variação das funções com seus teoremas e propriedades, o autor insere a noção de primitiva de uma função, a noção de integral de Riemann e os métodos de integração, o que lhe permite considerar os teoremas e as propriedades associados a essas noções e propor 
aplicações que, na maioria dos casos, podem ser consideradas exemplos intramatemáticos, isto é, exemplos em outros quadros da própria matemática, como a Geometria. Certamente, esse trabalho intramatemático exige um discurso tecnológico apropriado que o justifique.

O autor traz grande número de exemplos e exercícios de nível técnico, mas é importante lembrar que as técnicas de integração estão associadas aos conceitos de limite, derivada, funções e fatoração, que devem ser disponíveis aos estudantes para que estes sejam capazes de compreender essas técnicas e trabalhar com elas, ou seja, se o momento didático para introdução dessas técnicas corresponde ao primeiro momento, conforme definição de Chevallard (1997), os outros momentos aparecem associados aos conhecimentos retrospectivos necessários para o desenvolvimento das tarefas.

$\mathrm{O}$ autor também apresenta um grande número de exemplos em que os níveis mobilizável e disponível são necessários para a compreensão e solução da tarefa propriamente dita. Além disso, deve-se lembrar que o nível disponível comparece constantemente associado às noções anteriormente estudadas e que não são explicitadas no enunciado das tarefas propostas aos estudantes.

Trata-se de uma obra mais indicada a estudantes do curso de Matemática, para o que o autor tem o cuidado de trabalhar exemplos de outros quadros da própria Matemática, o que possibilita a articulação de quadros e pontos de vista e mostra a importância dos ostensivos e dos não ostensivos que estão em jogo nas tarefas, mesmo se o autor não considera explicitamente essas questões.

Quanto ao tema tratado neste artigo - cálculo de áreas, para o setor 'primitiva de uma função e integral de Riemann' -, identificamos que o conjunto de tarefas propostas aos estudantes permite-lhes articular conhecimentos retrospectivos desenvolvidos no Ensino Médio, mas isso pode exigir uma revisita a esses conhecimentos se estes não estiverem ainda disponíveis, ou seja, as praxeologias associadas ao cálculo de áreas exigem que os estudantes disponham de conhecimentos que ultrapassam a simples aplicação dos métodos de integração. Isso mostra a importância de trabalhar setores e domínios já no Ensino Médio para auxiliar os estudantes a articularem os diferentes conceitos e noções de Matemática e das outras ciências. 
Análise da obra Cálculo: um curso moderno e suas aplicações, de Laurence D. Hoffmann e Gerald L. Bradley (2002)

O livro introduz as noções de função, limite e derivada, sempre acompanhadas das técnicas necessárias às aplicações em diferentes áreas (Psicologia, Ciências Sociais, Economia, Física etc.).

Ao chegarem a este livro, os estudantes já desenvolvem efetivamente os três níveis de conhecimento e já têm o hábito de ir além do simples nível técnico, pois, na solução de problemas contextualizados de outros domínios, sabe-se que o nível de conhecimento necessário é o disponível. Mesmo que este não seja esperado para a aquisição da nova noção que está sendo trabalhada, ele estará relacionado a conhecimentos anteriores, como a noção de fatoração que é trabalhada no início do Ensino Fundamental.

Após a introdução das noções de função, limite e derivada e após um trabalho articulando esses conhecimentos e os conhecimentos anteriores dos estudantes nas aplicações propostas, os autores introduzem a noção de integral indefinida, seguindo o mesmo tipo de abordagem: após um desenvolvimento das técnicas associadas ao novo conceito, propõem aos estudantes exemplos e tarefas contextualizados de outras áreas, em que os níveis mobilizável e disponível serão trabalhados, havendo sempre a necessidade de um discurso tecnológico para planejar, desenvolver, justificar e controlar a solução proposta.

Como na obra anterior, observamos que, ao propor tarefas de aplicação em outras ciências, os autores dificultam ainda mais o tratamento do tema 'cálculo de áreas', pois, além de exigir conhecimentos retrospectivos desenvolvidos no Ensino Médio, ainda é geralmente preciso dispor de conhecimentos associados a essa ciência, o que nem sempre é o caso. Assim, da mesma forma que na obra anterior, no setor 'primitiva de uma função e integral de Riemann' são considerados os diferentes momentos didáticos de forma não hierárquica, como ressalta Chevallard (1997), em função da necessidade de utilização de conhecimentos retrospectivos desenvolvidos no Ensino Médio.

Também nesta obra identificamos haver articulação entre domínio, setor, tema e tópicos e observamos que os tipos de tarefas propostas aos estudantes, ou seja, as praxeologias desenvolvidas requerem que estes articulem seus conhecimentos retrospectivos com os novos conhecimentos para que sejam capazes de aplicá-los de forma consciente em novas tarefas escolares e profissionais.

Trata-se de uma obra que faculta ao professor fazer escolhas na aplicação em outras ciências, em função da diversidade de tarefas de aplicação nestas, mas que, como a obra 
anterior, exige que se trabalhem os três níveis de conhecimento, tanto para a nova noção que está sendo introduzida, quanto para as noções que se esperam disponíveis para os estudantes do Ensino Superior.

\section{Análise da prova do ENADE 2014 para o curso de Licenciatura em Matemática}

Na prova de matemática do ENADE 2014 para estudantes do curso de Licenciatura em Matemática (BRASIL, 2014), encontramos duas tarefas que estão em conformidade com os saberes desenvolvidos nos livros didáticos, em particular nas duas obras aqui analisadas. $\mathrm{O}$ nível de conhecimento esperado dos estudantes é o mobilizável em relação à noção de integral de Riemann e o disponível em relação aos métodos da substituição e integração por partes para a solução das integrais apresentadas explicitamente nas tarefas.

Dessa forma, o conjunto de praxeologias apresentadas nos livros didáticos, em particular em relação ao tema 'cálculo de áreas', quando se considera o setor 'primitiva de uma função e integral de Riemann', possibilita que o estudante articule os conhecimentos retrospectivos desenvolvidos no Ensino Médio e seja capaz de utilizá-los para responder às tarefas solicitadas no ENADE - ou seja, as relações pessoais esperadas dos estudantes estão em consonância com as relações institucionais, quando analisamos estas últimas por meio dos livros didáticos comumente apresentados nas bibliografias da disciplina 'Cálculo diferencial e integral' dos cursos de Licenciatura em Matemática.

\section{Conclusão}

A análise do funcionamento institucional por meio dos livros didáticos evidenciou existir uma preocupação em ultrapassar a simples definição e o desenvolvimento dos métodos de integração, pois nas duas obras analisadas verifica-se a preocupação de introduzir exemplos contextualizados de aplicações na própria Matemática ou em outros domínios. Observamos que os seis momentos definidos por Chevallard (1997) se sucedem no desenvolvimento das obras apresentadas e estão implícitos no desenvolvimento das praxeologias propostas, pois estas requerem a utilização de conhecimentos retrospectivos desenvolvidos no Ensino Médio.

Certamente, esse tipo de abordagem das noções de primitiva de uma função e de integral de Riemann ultrapassa o nível técnico das reproduções das tarefas, exigindo os níveis mobilizável e disponível, os quais estão associados à articulação dos conhecimentos já existentes com os novos conhecimentos, supondo uma organização desses conhecimentos de 
modo que os estudantes sejam capazes de utilizá-los de forma eficaz, sejam eles explicitamente pedidos na tarefa ou não.

O estudo do tema 'cálculo de área' para o setor 'primitiva de uma função e integral de Riemann' proposto nas obras analisadas coloca em evidência a importância da não restrição aos níveis de tema e de tópico, ou seja, indica a necessidade de um trabalho que não se condicione à reprodução e ao privilégio de determinadas praxeologias em detrimento da articulação com outros domínios do conhecimento.

Essa realidade deve ser considerada quando se deseja que os estudantes alcancem uma aprendizagem com significado, o que indica a necessidade de dispor de diferentes formas e métodos para o desenvolvimento de determinado conteúdo, em particular quando se pretende trabalhar com tarefas para as quais não basta referir-se a uma definição (nível técnico) ou identificar ou organizar esses conhecimentos (nível mobilizável), mas sim ser capaz de articulá-los com conhecimentos de outros quadros, utilizar diferentes pontos de vista e diferentes ostensivos, estabelecer relações, aplicar novos métodos e até criar exemplos (nível disponível).

\section{Referências}

BOSCH, M.; CHEVALLARD, Y. La sensibilité de l'activité mathématique aux ostensifs. Recherches en didactique des mathématiques, Grenoble, v. 11, n. 1, p. 77-123, 1999.

BRASIL. ENADE (2014). Exame Nacional de Desempenho dos Estudantes. Disponível em:

<http://download.inep.gov.br/educacao_superior/enade/provas/2014/34_matematica_licenciat ura.pdf >. Acesso em: 12 mar. 2015.

CHEVALLARD, Y. Concepts fondamentaux de la didactique: perspectives apportées par une approche anthropologique. Recherches en didactique des mathématiques, Grenoble, v. 12, n. 1, p. 73-112, 1992.

CHEVALLARD, Y. Ostensifs et non-ostensifs dans l'activité mathématique. 1994.

Disponível em: $<$ http://yves.chevallard.free.fr/spip/spip/article.php3?id_article=125 >. Acesso em: 10 fev. 2015.

CHEVALLARD, Y. Familière et problématique, la figure du professeur. Recherches en didactique des mathématiques, Grenoble, v. 17, n. 3, p. 17-54, 1997.

CHEVALlARD, Y. Les outils sémiotiques du travail mathématique, Petit-x, n. 42, p. 33-57, 1996. 
CHEVALLARD, Y. Organisations Didactiques: 1. Les Cadres Généraux, 1998. Disponível em: <http://yves.chevallard.free.fr/spip/spip/article.php3 ?id_article=38 >. Acesso em: 08 mar. 2015.

CHEVALLARD, Y. Organiser l'étude : 3 . Ecologie \& régulation. XIe école d'été de didactique des mathématiques (Corps, 21-30 de agosto de 2001) (pp. 41-56). Grenoble: La Pensée Sauvage, 2002.

CHEVALLARD, Y. Le développement actuel de la TAD. Pistes et jalons, 2007. Disponível em: <http://yves.chevallard.free.fr/spip/spip/article.php3?id_article=150 >. Acesso em: 20 fev. 2015.

CHEVALLARD, Y. Théorie Anthropologique du Didactique \& Ingénierie Didactique du Développement. 2012. Disponível em:

<http://yves.chevallard.free.fr/spip/spip/article.php3?id_article=212 >. Acesso em: 05 fev. 2015.

DOUADY, R. Des apports de la didactique des mathématiques à l'enseignement. Repères IREM, n.15, p. 37-61, 1992.

DOUADY, R. Jeux de cadre et dialectique outil objet dans l'enseignement des mathématiques. 340f. Doutorado (Didática da Matemática) - Universidade Paris Diderot, Paris, 1984.

GUIDORIZZI, H. L. Um curso de cálculo. 5. ed. Rio de Janeiro: LTC, 2004.

HOFFMANN, L. D.; BRADLEY, G. L. Cálculo: Um curso moderno e suas aplicações. 7. ed. Rio de Janeiro: LTC, 2002.

ROBERT, A. Outils d'analyse des contenus mathématiques à enseigner au lycée et à l'université. Recherches en Didactique des Mathématiques, Grenoble, v. 18, n. 2, p. 139190, 1998.

ROBERT, A. Quelques outils d'analyse épistémologique et didactique de connaissances mathématiques à enseigner au lycée et à l'université. In: IX Ecole d'été de didactique des mathématiques, 1997, Houlgate. Actes de la IX école d'été de didactique des mathématiques. Houlgate: ARDM, 1997, p. 192-212.

ROGALSKI, M. Les changements de cadre dans la pratique des mathématiques et le jeu de cadres de Régine Douady. In: Journée en hommage à Régine Douady, 2001, Paris. Actes de la journée en hommage à Régine Douady. Paris: DIDIREM, 2001, p. 13-26.

ROGALSKI, M. Notes du seminaire à São Paulo. Brasil, 1995.

THURSTON, W. P. Preuve et progrès en mathématiques. Repères IREM, n. 21, p. 5-36, 1995. 